\title{
Bone marrow cell derived arginase I is the major source of allergen-induced lung arginase but is not required for airway hyperresponsiveness, remodeling and lung inflammatory responses in mice
}

\author{
Kathryn A Niese ${ }^{1}$, Ann R Collier ${ }^{1}$, Amanda R Hajek ${ }^{1}$, Stephen D Cederbaum², \\ William E O'Brien³, Marsha Wills-Karp ${ }^{4}$, Marc E Rothenberg1 and \\ Nives Zimmermann*1
}

Address: ${ }^{1}$ Division of Allergy and Immunology, Cincinnati Children's Hospital Medical Center and the University of Cincinnati College of Medicine, Cincinnati, Ohio, USA, ${ }^{2}$ Division of Genetics, Department of Pediatrics, University of California Los Angeles Medical Center, Los Angeles, California, USA, ${ }^{3}$ Department of Molecular and Human Genetics, Baylor College of Medicine, Houston, Texas, USA and ${ }^{4}$ Division of Immunobiology, Cincinnati Children's Hospital Medical Center and the University of Cincinnati College of Medicine, Cincinnati, Ohio, USA

Email: Kathryn A Niese - Kathryn.Niese@cchmc.org; Ann R Collier - arzcollier@yahoo.com; Amanda R Hajek - ahajek2@illinois.edu; Stephen D Cederbaum - scederbaum@mednet.ucla.edu; William E O'Brien - wobrien@bcm.edu; Marsha Wills-Karp - Marsha.WillsKarp@cchmc.org; Marc E Rothenberg - Rothenberg@cchmc.org; Nives Zimmermann* - Nives.Zimmermann@cchmc.org

* Corresponding author

Published: I June 2009

BMC Immunology 2009, 10:33 doi:10.1 186/1471-2172-10-33
Received: 30 January 2009

Accepted: I June 2009

This article is available from: http://www.biomedcentral.com/147I-2172/10/33

(c) 2009 Niese et al; licensee BioMed Central Ltd.

This is an Open Access article distributed under the terms of the Creative Commons Attribution License (http://creativecommons.org/licenses/by/2.0), which permits unrestricted use, distribution, and reproduction in any medium, provided the original work is properly cited.

\begin{abstract}
Background: Arginase is significantly upregulated in the lungs in murine models of asthma, as well as in human asthma, but its role in allergic airway inflammation has not been fully elucidated in mice.

Results: In order to test the hypothesis that arginase has a role in allergic airway inflammation we generated arginase I-deficient bone marrow (BM) chimeric mice. Following transfer of arginase Ideficient BM into irradiated recipient mice, arginase I expression was not required for hematopoietic reconstitution and baseline immunity. Arginase I deficiency in bone marrow-derived cells decreased allergen-induced lung arginase by $85.8 \pm 5.6 \%$. In contrast, arginase II-deficient mice had increased lung arginase activity following allergen challenge to a similar level to wild type mice. BM-derived arginase I was not required for allergen-elicited sensitization, recruitment of inflammatory cells in the lung, and proliferation of cells. Furthermore, allergen-induced airway hyperresponsiveness and collagen deposition were similar in arginase-deficient and wild type mice. Additionally, arginase II-deficient mice respond similarly to their control wild type mice with allergen-induced inflammation, airway hyperresponsiveness, proliferation and collagen deposition.

Conclusion: Bone marrow cell derived arginase I is the predominant source of allergen-induced lung arginase but is not required for allergen-induced inflammation, airway hyperresponsiveness or collagen deposition.
\end{abstract}




\section{Background}

Asthma is a serious, chronic inflammatory disorder that is responsible for one in six pediatric emergency room visits, is the $3^{\text {rd }}$ leading cause of hospitalization among children and is one of the leading causes of school absenteeism. In the United States, nearly 30\% of the population suffers from allergies with 5-10\% inflicted with asthma. Despite intense ongoing asthma research, there is currently an epidemic of this disease in the western world and the incidence is on the rise $[1,2]$. The pathophysiology of asthma is characterized by eosinophil-rich inflammatory cell infiltrates, increased mucus production, airway hyperreactivity, and reversible airway obstruction [3-5]. Experimentation in the asthma field has largely focused on analysis of the cellular and molecular events induced by allergen exposure in sensitized animals (primarily mice) and humans. While these studies have provided the rationale for the development of multiple therapeutic agents that interfere with specific inflammatory pathways [6], the development of the asthma phenotype is likely to be related to the complex interplay of a large number of additional genes, and their polymorphic variants.

Accordingly, in an effort to identify new genes involved in the pathogenesis of asthma, we reported a group of genes that was induced in the lungs in two phenotypically similar models of experimental asthma triggered by independent regimes $[7,8]$. Among these asthma signature genes, we found overexpression of genes encoding for enzymes and transporters involved in arginine metabolism, specifically arginase I, arginase II and CAT2 [7]. We chose to focus on these genes because intracellular arginine is a regulator of diverse pathways including production of nitric oxide, polyamines, and proline; these molecules regulate critical processes associated with asthma including airway tone, cell hyperplasia and collagen deposition, respectively $[9,10]$. Furthermore, recent studies have shown a role for arginase in several parasitic models [11-16], commonly associated with Th2/M2 inflammation. Finally, recent studies with arginase inhibitors suggested an effect on outcomes of allergic airway inflammation in mice and guinea pigs [17-19]. However, the results of these studies were contradictory with one study suggesting a protective and the other two a detrimental role for arginase in allergen-induced inflammation and airway hyperresponsiveness. Altogether, we tested the hypothesis that arginase expression has a role in allergic airway inflammation by subjecting arginase I-deficient bone marrow chimeric mice and arginase II-deficient mice to allergen challengeinduced airway inflammation. We demonstrate that arginase I expression does not affect bone marrow reconstitution following transfer into lethally irradiated recipients and that arginase is not required for baseline immunity. We also demonstrate that $\mathrm{BM}$-derived arginase $\mathrm{I}$ is the main source of allergen-induced lung arginase. However, our studies demonstrate that arginase is not required for allergen-induced airway inflammation, hyperresponsiveness or collagen deposition.

\section{Methods}

\section{Generation of arginase I bone marrow (BM) chimeras}

All animal studies were approved by the CCHMC IACUC committee. Arginase I heterozygous mice [20] were bred and pups were genotyped 7-9 days after birth. Bone marrow was collected from arginase I -/- pups and heterozygous or wild type (majority of experiments) pups (postnatal day 9-12). No difference was observed in experiments where +/- versus +/+ mice were used as control. In early experiments we transferred $1 \times 10^{6}$ total bone marrow cells, and in later ones $2 \times 10^{5}$ low density bone marrow cells were used. No difference in engraftment was observed with the two methods. Recipient mice (CD45.1 congenic mice) were irradiated [ 2 doses of ${ }^{137} \mathrm{Cs}$ (700 and 475 rads) 3 hours apart] and bone marrow injected i.v. Engraftment was checked by CD45.1 (recipient)/CD45.2 (donor) on peripheral blood by flow cytometry (antibodies from BD Pharmingen specific for CD45.1 and CD45.2 are clones A20 and 104, respectively)) and allergen challenges started 8-14 weeks post-irradiation. In some experiment, $\mathrm{C} 57 \mathrm{Bl} / 6$ mice were used as recipients and thus chimerism was not checked prior to the allergen challenge. However, in all experiments we verified that arginase activity was not induced in the lung of allergenchallenged arginase I BM chimeric mice (see results). As an additional control, in some experiments we used mice that were not irradiated and bone marrow transferred (non-BMT). Finally, we backcrossed arginase I-heterozygous mice for 6 generations on the BALB/c background and verified findings obtained with $\mathrm{C} 57 \mathrm{Bl} / 6$ mice (specifically, the expression of arginase I in the lung by Northern blot analysis, airway hyperresponsiveness and BALF cellularity). Since congenic mice were not used to check engraftment with BALB/c mice, we verified lack of arginase I expression in the lung by Northern blot analysis.

\section{Induction of allergic airway inflammation}

Arginase I BM chimeras and Arginase II-deficient mice [21] were allergen challenged using two models, as described previously $[7,8,22]$. Briefly, in the first model, mice were sensitized i.p. with ovalbumin (OVA, $100 \mu \mathrm{g}$ ) in alum ( $1 \mathrm{mg}$ ) and challenged intranasally (i.n.) with 50 $\mu \mathrm{g}$ OVA or saline. Aspergillus fumigatus antigen-associated asthma was induced by challenging mice intranasally three times a week for three weeks, as described [23-25]. In brief, mice were lightly-anesthetized with isofluorane inhalation and $100 \mu \mathrm{g}(50 \mu \mathrm{l})$ of Aspergillus fumigatus extract (Bayer Pharmaceuticals, Spokane, WA) or $50 \mu \mathrm{l}$ of normal saline alone was applied to the nasal cavity using a micropipette with the mouse held in the supine position. After instillation, mice were held upright until alert. Mice were sacrificed 18-24 hours following the last challenge. 


\section{Arginase activity}

Arginase activity was measured using the blood urea nitrogen reagent (Sigma Chemical Company, St. Louis, MO) according to established techniques [26-28].

\section{In situ hybridization of mouse lung}

In situ hybridization was performed as described [7]. In brief, murine arginase I cDNA in plasmid pCMV-SPORT6 (Incyte Genomics, St. Louis, MO) was linearized by EcoRI or Not I digestion, and anti-sense and sense RNA probes, respectively, were generated by T7 and SP6 RNA polymerase (Riboprobe Gemini Core System II transcription kit; Promega, Madison, WI). The radiolabeled [ $\alpha S^{35}$-UTP] probes were hybridized and washed under high-stringency conditions.

\section{Northern blot analysis}

RNA was extracted using the Trizol reagent as per the manufacturer's instructions. The cDNA probes, generated by PCR or from commercially available vectors [Image Consortium obtained from American Tissue Culture Collection, Rockville, MD or Incyte Genomics, Palo Alto, CA], were sequence confirmed, radiolabelled with ${ }^{32} \mathrm{P}$, and hybridized using standard conditions, as described previously [7].

\section{Measurement of airway hyperreactivity}

Allergen-induced AHR was determined as described previously [29,30]. Briefly, mice were anesthetized, intubated and ventilated at a rate of 120 breaths per minute with a constant tidal volume of air $(0.2 \mathrm{ml})$, and paralyzed with decamethonium bromide $(25 \mathrm{mg} / \mathrm{kg})$. After establishing a stable airway pressure, $25 \mu \mathrm{g} / \mathrm{kg}$ weight of acetylcholine was injected i.v. and dynamic airway pressure (airway pressure time index [APTI] in $\mathrm{cm} \mathrm{H}_{2} \mathrm{O} / \mathrm{sec}$ ) was followed for 5 minutes.

\section{Measurement of collagen accumulation}

Collagen accumulation was determined as described previously [31]. Briefly, the upper, left lobe of lung was homogenized in $0.5 \mathrm{M}$ acetic acid. Following the addition of pepsin ( $1 \mathrm{mg} / 10 \mathrm{mg}$ tissue, Sigma), the lung homogenates were vigorously shaken overnight at $4{ }^{\circ} \mathrm{C}$. Collagen content was determined biochemically by quantifying total soluble collagen using the Sircol collagen assay kit (Biocolor Ltd, Newtownabbey, Northern Ireland) according to the manufacturer's instructions. The data are expressed as the collagen content normalized per mouse weight. In other experiments, we measured collagen accumulation by measuring the content of hydroxyproline, as previously described [32].

\section{Antigen-specific antibody measurement}

Plasma OVA-specific $\operatorname{IgG}_{1}$ was measured after coating the wells with OVA $(100 \mu \mathrm{g} / \mathrm{ml})$. Blocking was done with $10 \%$ FBS in PBS, and all washes were performed with
0.1\% Tween-20 in PBS. Plasma samples were diluted $1: 1000$ and then serially diluted 1:4. After 2 hours of incubation, plates were washed and HRP-conjugated antimouse IgG1 $(1: 1,500)$ (X56; BD PharMingen) was added. The OD was read at $450 \mathrm{~nm}$ within 10 minutes.

\section{Ki67 staining and quantification}

Tissues were fixed in 10\% neutral buffered formalin and paraffin embedded. Immunohistochemistry analysis was performed on deparaffinized $5 \mu \mathrm{m}$ sections after blocking of endogenous peroxidase activity, antigen retrieval (in citrate buffer (pH6) in microwave oven for $7 \mathrm{~min}$ ) and blocking with normal goat serum. The primary antibody [antiKi67 1:50 (clone B56, BD PharMingen)] was diluted in $0.1 \%$ bovine serum albumin in PBS, applied to tissue sections, and incubated overnight at $4{ }^{\circ} \mathrm{C}$. Antibody staining was detected with biotinylated anti-mouse IgG secondary antibody and Vectastain ABC, MOM Immunodetection, and DAB Substrate kits (Vector Laboratories, Inc.). Sections were counterstained with nuclear fast red. Counts represent evaluation of an average number of cells per $\mathrm{mm}^{2}$ determined by an observer blinded to treatment and genotype using Metamorph software.

\section{Statistical analysis}

The significance of differences between groups were analyzed using two-way (disease and genotype) ANOVA using Prism software. Values are reported as the mean \pm standard deviation. Differences are considered significant if $\mathrm{P}<0.05$. Pairwise comparisons were performed by Student's t-test and $P$ values are shown in the figures.

\section{Results \\ Development of arginase I-deficient bone marrow chimeras}

Arginase I-deficient mice [20] develop severe hyperammonemia and die between postnatal days 10 and 14. Since we have previously demonstrated that arginase I expression in allergic airway inflammation is located in macrophages [7], we developed bone marrow chimeras with arginase I-deficient bone marrow derived from arginase I-deficient pups. In experiments where congenic CD45.1 mice were used as recipients, we evaluated donor (CD45.2) chimerism in the peripheral blood at monthly intervals prior to commencing allergen challenges. Importantly, there was no difference in engraftment of arginase I-deficient and wild type bone marrow (for instance, in a representative experiment there were $92.14 \pm 1.46$ and $91.13 \pm 2.64 \%$ donor-derived cells, respectively; $\mathrm{n}=7-8$ mice, $\mathrm{P}=0.38$ ) demonstrating that arginase I expression did not affect bone marrow reconstitution following bone marrow transfer.

\section{Bone marrow-derived arginase $I$ is not required for basal immunity}

Since previous studies have demonstrated that arginase transgenic mice have defective $\mathrm{B}$ cell maturation and 
impaired development of Payer's patches [33,34], we analyzed chimeric mice for basic hematological and immunological parameters. We found that mouse body weight, spleen weight, complete blood counts, engraftment of individual cell types (CD4, CD8 and B220-positive cells) were not dependent on arginase expression in BM-derived cells (data not shown). Peyer's patches were not detectable macroscopically following irradiation irrespective of arginase expression. In summary, we demonstrate that bone marrow-derived arginase I is not required for baseline immune cell development.

\section{Bone marrow-derived arginase $I$ is not required for adaptive immunity}

7-14 weeks post-irradiation, mice were challenged with allergen. We used two models of allergic airway inflammation, as we have shown arginase I and II are increased in both models and are part of the "asthma signature genome" $[7,8]$. Importantly, while these two independent models use different antigens and routes of sensitization, the phenotype in mice is similar $[7,8]$. In the first model, mice are sensitized intraperitoneally (i.p.) with OVA and adjuvant alum and then challenged intranasally with OVA or saline for control. In the second model, mice were sensitized and challenged mucosally (by the intranasal route) with Aspergillus fumigatus extract. First, we verified that sensitization is not affected by arginase I deficiency. We measured OVA-specific IgG1 in OVA-sensitized mice and determined that deficiency of arginase I in bone marrowderived cells did not affect systemic sensitization (Figure $1 \mathrm{~A})$, which is consistent with our finding that the hematological and immunological parameters are grossly normal in these mice. Similarly, OVA-specific IgE was not affected by arginase I expression in bone marrow derived cells (data not shown).

\section{Bone marrow arginase $I$ is the main source of allergen- induced lung arginase}

We hypothesized that bone marrow-derived cells are required for arginase expression in the lung of allergenchallenged mice. As seen in Figure 1B, Northern blot analysis for arginase I indeed shows decreased expression of arginase I in arginase I chimeric mice (wild type mice transplanted with arginase I-deficient bone marrow). Similarly, in situ hybridization of allergen-challenged arginase I-deficient BM chimeric mice demonstrated a significant decrease in the number of arginase I-expressing cells compared to mice that received arginase I +/- bone marrow cells. (Figure 1C). In order to verify that the arginase I BM chimeras indeed are deficient in lung arginase, we measured arginase activity in allergen-challenged mice. As shown in Figure 1D, Aspergillus-challenged non-BMT mice and arginase + + + BM chimeras induce arginase activity in the lung. However, arginase I-deficient BM chimeras did not show increased arginase activity with allergen challenge. Similar results were seen in the OVA model (data not shown). We have shown that both arginase I and arginase II expression are increased in allergen challenged mice [7]. In order to test the hypothesis that arginase I is the main contributor to the observed increase in arginase activity in allergen-challenged mice, we measured arginase activity in allergen-challenged arginase IIdeficient mice. As seen in Figure 1E, arginase activity was increased in the lungs of arginase II-deficient mice to a level similar to wild type mice. In summary, these data demonstrate that arginase I is primarily induced in bone marrow-derived cells and that arginase I expression predominantly contributes to allergen-elicited arginase activity in the allergic lung.

\section{Disease outcomes in allergic airway inflammation}

We were first interested if arginase I has a role in inflammation and cell recruitment in allergic airway inflammation. Cells in the BALF were differentiated based on morphology and we demonstrate that arginase I BM chimeras had similar allergen-elicited recruitment of inflammatory cells (Figure 2A-B). Similar results were obtained in arginase I-deficient BM chimeras on the BALB/c background with OVA and Aspergillus-induced allergic inflammation. Furthermore, we assessed the expression of cytokines and chemokines known to be induced by allergen challenge. Northern blot analysis demonstrated induction of eotaxin-2, TARC, 15-lypoxygenase and small proline rich protein 2 (SPRR2) by OVA irrespective of arginase I expression in the lungs (data not shown). Furthermore, the protein level of eotaxin-1, MIG, RANTES, IL-4, IL-5 and leukemia inhibitory factor (LIF) were induced by Aspergillus in the lungs of mice irrespective of arginase I (data not shown). These data demonstrate that arginase I is not required for the development of inflammation in allergic lung inflammation.

Arginase can compete with NOS for substrate, arginine, and can thus lead to decreased production of NO. As NO has been shown to regulate airway tone, we tested the hypothesis that arginase I has a role in allergen-induced airway hyperreactivity (AHR). For these studies, we used only the Aspergillus model which consistently induced AHR in allergen-challenged C57Bl/6 mice. As seen in Figure 2C, Aspergillus-challenged non-BMT and arginase I +/ $+\mathrm{BM}$ chimeras demonstrate increased responsiveness to acetylcholine, compared to their respective saline-challenged controls. Interestingly, even in the absence of arginase I activity in the lung, mice displayed AHR. Similar results were obtained with arginase I-deficient BM chimeras on the $\mathrm{BALB} / \mathrm{c}$ background. These data demonstrate that arginase I is not required for allergen-induced AHR.

Arginase metabolizes arginine to urea and ornithine which can further be metabolized by ornithine ami- 
A.

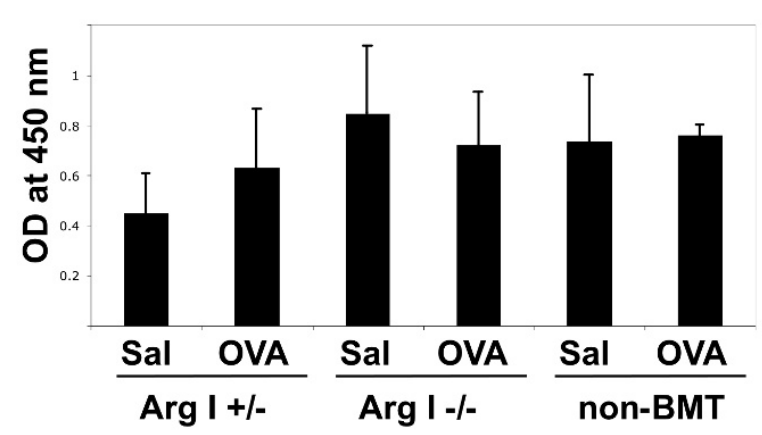

C.
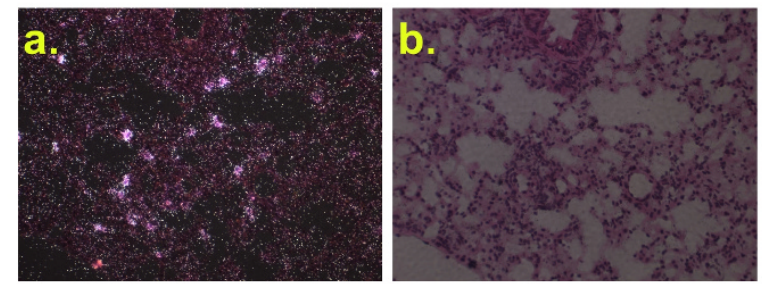

c.

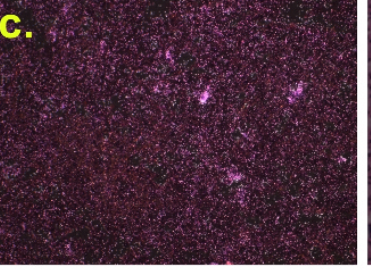

D. Arginase I BM chimeras

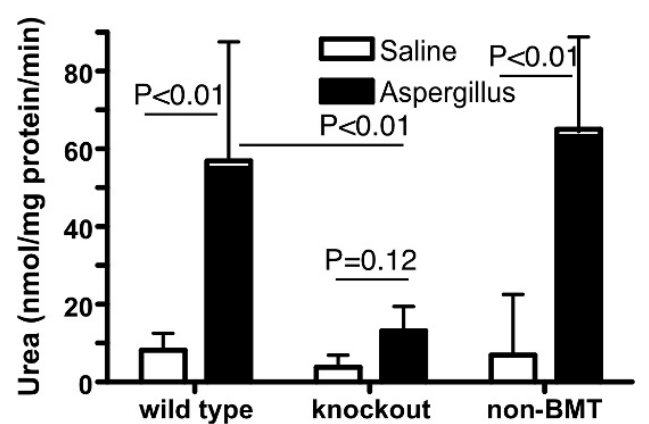

B.

Asp

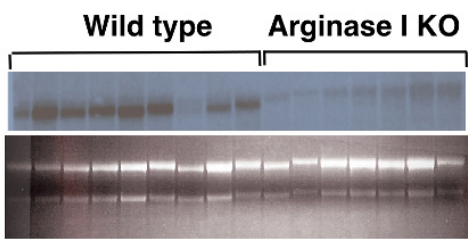

Arginase I KO Wild type

OVA Sal OVA

OVA

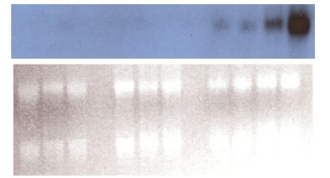

\section{E. Arginase II-deficient mice}

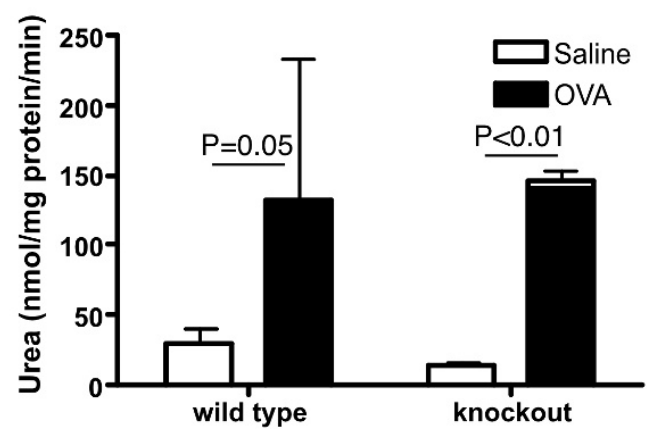

Figure I

Characterization of arginase I-deficient BM chimeric mice. In A, OVA-specific IgG I was measured in plasma. Representative experiment (2-4 mice per group) of 3 experiments performed is shown. In B, Northern blot analysis for arginase $I$ in allergen-challenged (OVA- ovalbumin model and Asp- Aspergillus fumigatus model) wild type and arginase I-deficient BM chimeras is shown. Ethidium bromide-stained gel is shown as loading control. In C, in situ hybridization with arginase I anti-sense probe is shown. Panels (a) and (b) are from an allergen-challenged arginase I +/- BM chimeric mouse and (c) and (d) are from an allergen-challenged arginase I -/- BM chimeric mouse. (a) and (c) are dark-field and (b) and (d) are bright-field images of the same area. Representative micrographs of 3 mice in each group are shown. In D and $E$, arginase activity on lung homogenates is shown. Representative of 4 experiments ( 2 with OVA and 2 with Asp) for arginase I chimeras, and 3 for arginase II-deficient mice are shown. Data are from 2-6 mice per group in the individual experiment with 7-I5 total mice per group. For both arginase I chimeras and arginase II-deficient mice, two-way ANOVA demonstrated a statistically significant $(P<0.0 \mathrm{I})$ effect of treatment (allergen compared to saline), with no statistically significant effect of interaction $(P>0.05)$. The $P$ value for the effect of genotype was $P=0.055$ in arginase I BM chimeras and $P=0.98$ in arginase II-deficient mice. 
notransferase to proline, an amino acid that is often the rate-limiting substrate for collagen synthesis [35-37]. Thus, we tested the hypothesis that arginase I has a role in allergen-induced collagen deposition. For these studies, we used only the Aspergillus model which demonstrates significant allergen-induced collagen deposition. As seen in Figure 2D, we observed increased collagen deposition in non-BMT mice, as well as in arginase I-deficient and sufficient BM chimeras. On average, there was a $39.2 \pm 5 \%$ and $58.8 \pm 9 \%$ allergen-induced increase in wild type and arginase I-chimeric mice, respectively $(\mathrm{P}=0.47, \mathrm{n}=10-16$ mice per group). These data demonstrate that arginase I is not required for allergen-induced collagen accumulation.

Ornithine, the metabolite of arginase activity, can serve as substrate for ornithine decarboxylase, leading to production of polyamines, which plan an important role in proliferation of cells. Thus, we tested the hypothesis that arginase I has a role in allergen-induced cell proliferation. As seen in Figure 2E-F, we observed increased numbers of Ki67-positive cells in allergen-challenged mice. These levels were comparable irrespective of arginase expression. Thus, these data demonstrate that arginase I is not required for allergen-induced proliferation.

\section{Arginase II- deficient mice}

It remained possible that arginase II is the critical arginase isoform in outcomes of allergic lung inflammation. The subcellular localization and presumed function of the two isoforms is different with arginase II expressed in the mitochondria (while arginase I is cytoplasmic) and predominantly implicated in biosynthetic pathways (while arginase I is predominantly thought to be involved in the urea cycle). Thus, we allergen challenged arginase II-deficient mice [21] and analyzed for outcomes of allergic airway inflammation. As seen in Figure 3A, arginase IIdeficient mice had allergen-induced BALF cell accumulation comparable to arginase II-wild type mice. Similarly, the arginase II-deficient mice had levels of allergeninduced airway hyperreactivity similar to wild type mice (Figure 3B). Furthermore, collagen deposition was induced in arginase II-deficient mice to levels comparable to those of arginase II-wild type mice (Figure 3C). Finally, proliferation of cells was not affected by the presence of arginase II (Figure 3D). Importantly, arginase activity in the lung was induced to similar levels in arginase II-deficient and wild type mice (Figure 1E). Thus, these data demonstrate that arginase II is not required for allergeninduced airway inflammation, AHR, collagen deposition and proliferation.

\section{Discussion}

The alternative pathway of macrophage activation, via IL4 , has been recently appreciated in many Th2-associated responses, such as parasitic infections and allergic inflam- mation. However, the role of these cells and their effectors in the broad spectrum of Th2-associated pathological processes is poorly understood. We investigated the role of the enzyme arginase, which is a marker of alternatively activated macrophages and highly upregulated in allergic and parasitic infection. While the role of arginase in the urea cycle is well understood, its role in inflammation is less clear. Based on known downstream mediators, arginase has been speculated to play a role in NO production and subsequent inflammation and regulation of airway tone, as well as proliferation and collagen synthesis via ornithine production. We used arginase I-deficient bone marrow chimeric mice in models of allergic airway inflammation. Use of arginase I BM chimeric mice revealed several novel findings. First, we demonstrate that arginase I expression does not affect bone marrow reconstitution following transfer into lethally irradiated recipients and that arginase is not required for baseline immunity. Second, we demonstrate that BM-derived arginase I is the main source of allergen-induced lung arginase. Third, we found that lung arginase is dispensable for regulation of inflammation, airway tone, fibrosis and cell proliferation during allergic airway inflammation.

Studies using arginase transgenic mice have demonstrated that overexpression of arginase (specifically in gut epithelial cells) leads to interrupted development of B cells and impaired Peyer's patch architecture [33,34]. Mechanistic analysis suggested that the hypoargininemia was responsible for the phenotype as arginine supplementation reversed the changes. Thus, it was important to assure that extrahepatic arginase deficiency does not perturb bone marrow engraftment and baseline immune parameters. We show here that genetic deficiency of arginase in bone marrow-derived cells does not affect BM engraftment, baseline and adaptive immunity. Thus, we speculate that excessive and/or systemic expression of arginase, such as in transgenic mice overexpressing arginase may affect the immune system via decreasing systemic arginine levels; however, lack of extrahepatic arginase does not appear to grossly affect the immune system.

Previous studies have suggested that macrophages are the main source of arginase in the allergen challenged mouse lung. However, other cell types, including respiratory epithelial cells have been implicated as potential sources of arginase [7,38-40]. Furthermore, we and others have shown that both arginase I and II expression is increased in the lungs following allergen challenge [7]. Thus, it remained possible that arginase II will contribute to lung arginase activity in allergen challenged arginase I BM chimeric mice. Our studies measuring arginase activity in both arginase I BM chimeric and arginase II-deficient mice demonstrated that arginase I, expressed in bone marrow cells, is the main contributor to arginase activity in allergic 
A.

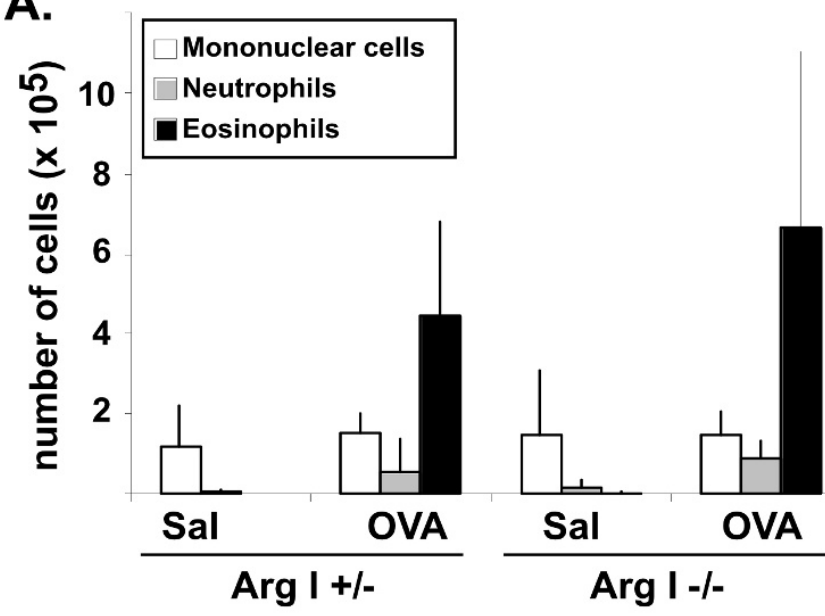

B.

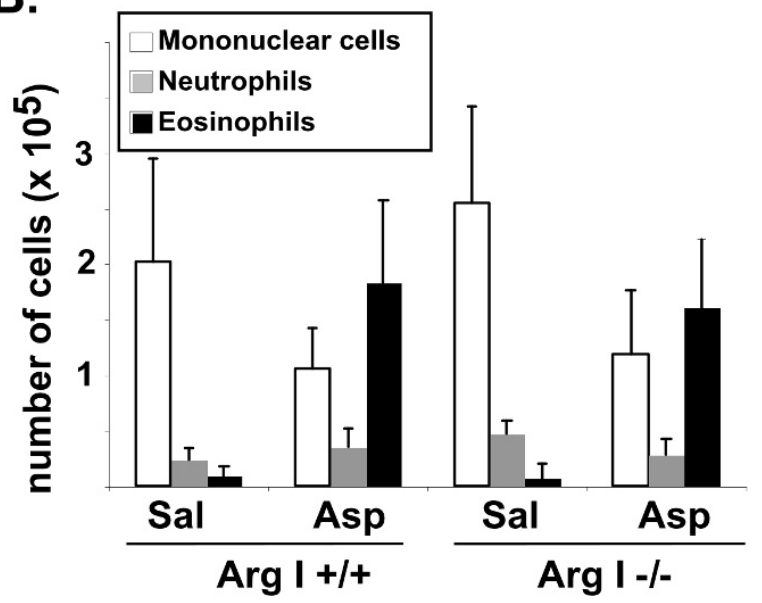

C.

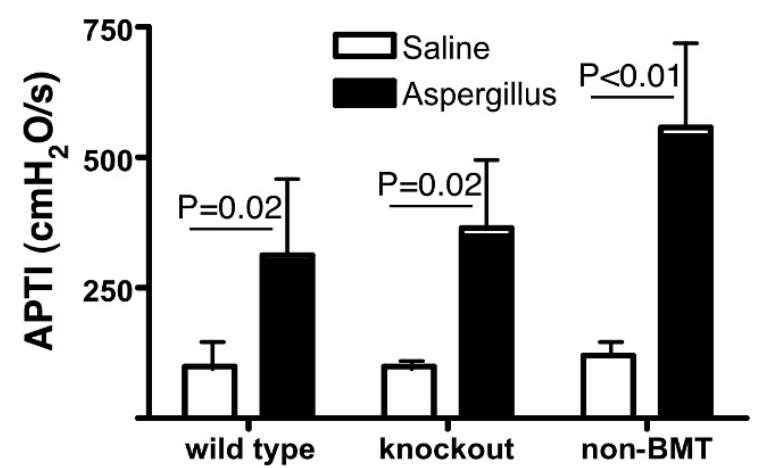

E.

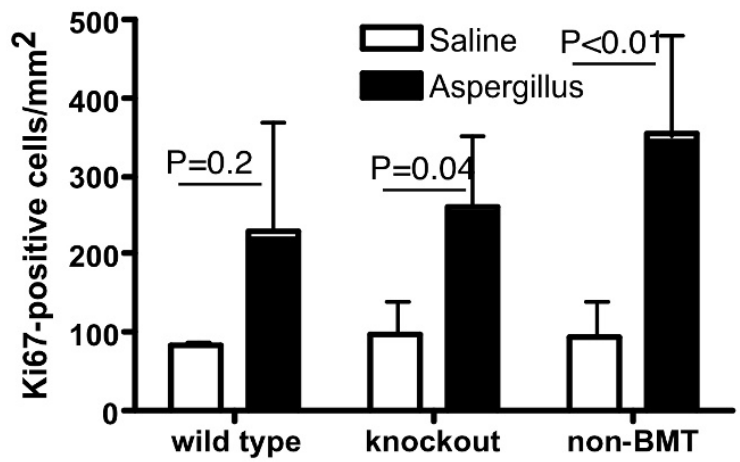

D.

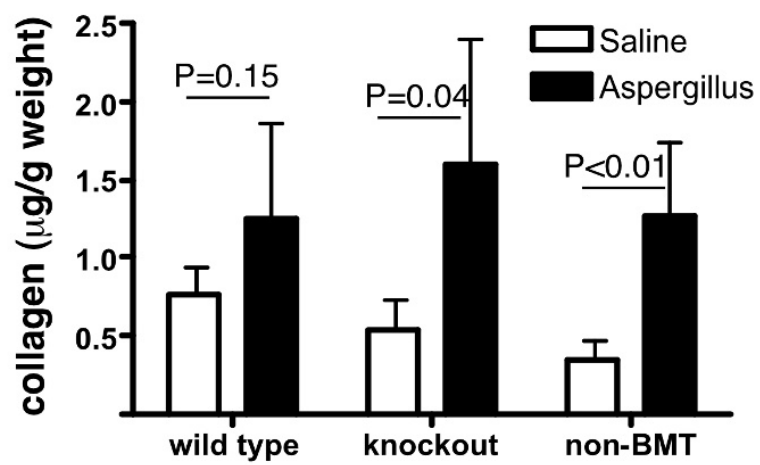

F.

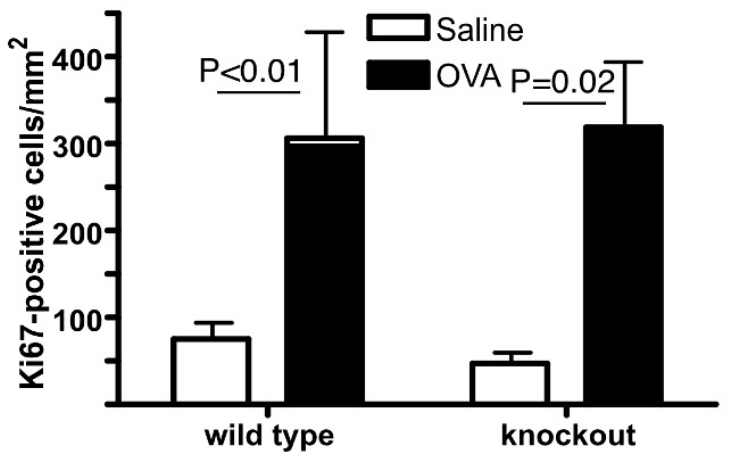

Figure 2

Disease outcomes in arginase I-deficient BM chimeric mice. In A and B, cell composition of the BALF is shown from OVA and Aspergillus model experiments. Data are from 2-4 (OVA model) and 3-II (Asp model) mice per group. In C, airway hyperresponsiveness is shown. Data are from 3-6 mice per group. In D, collagen content of the lung is shown. Data are from 4-6 mice per group. In $\mathrm{E}$ and $\mathrm{F}$, quantification of Ki67-positive cells by immunohistochemistry in Asp and OVA model respectively, is shown. Data are from 2-6 mice/group. In C-F, two-way ANOVA demonstrated a statistically significant $(P<0.00 I)$ effect of treatment (allergen compared to saline), with no statistically significant effect of genotype or interaction ( $P>0.05)$. In each panel, a representative experiment out of three performed is shown. 
A.

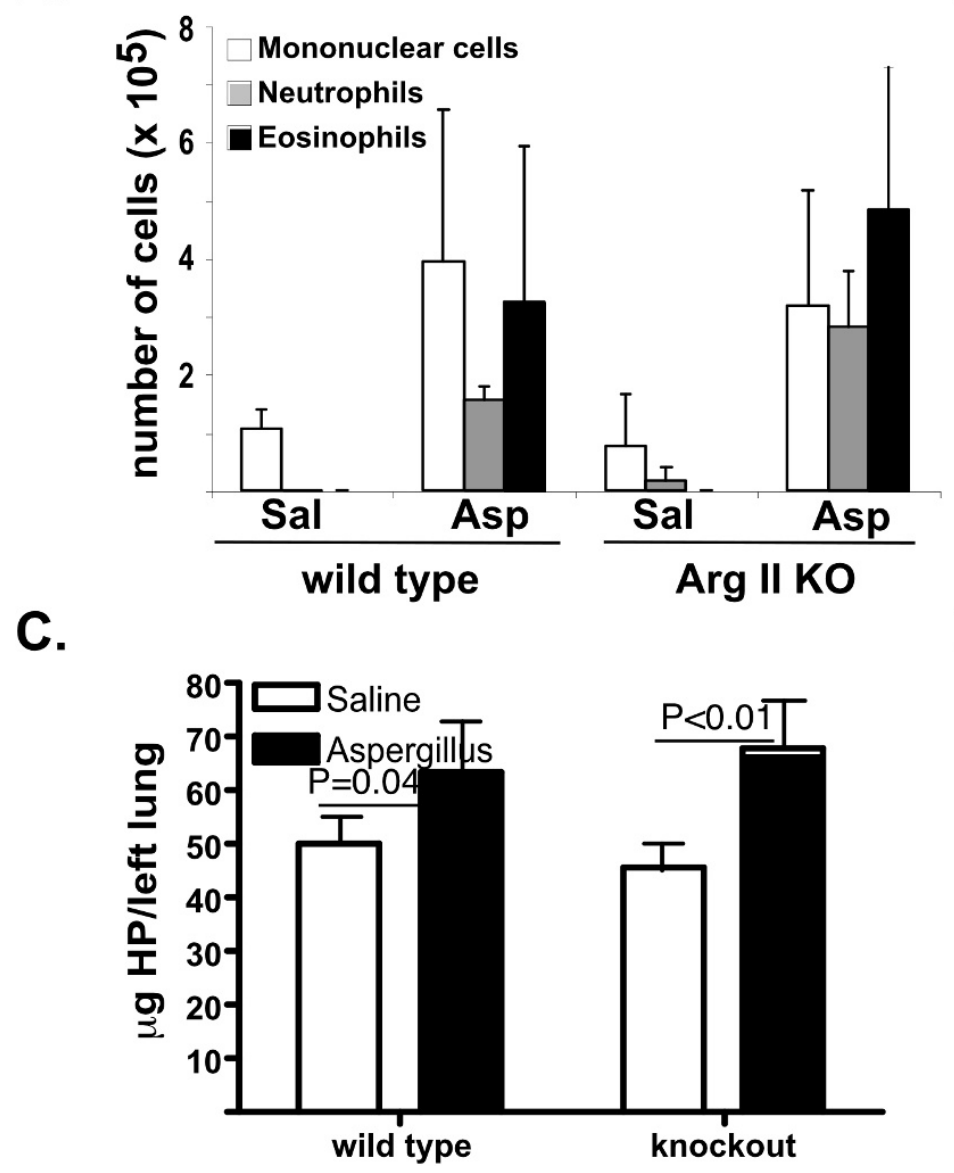

B.

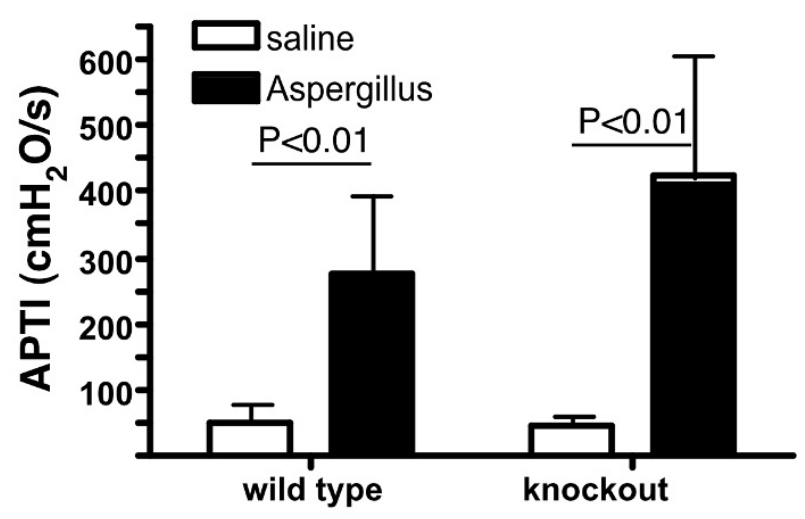

D.

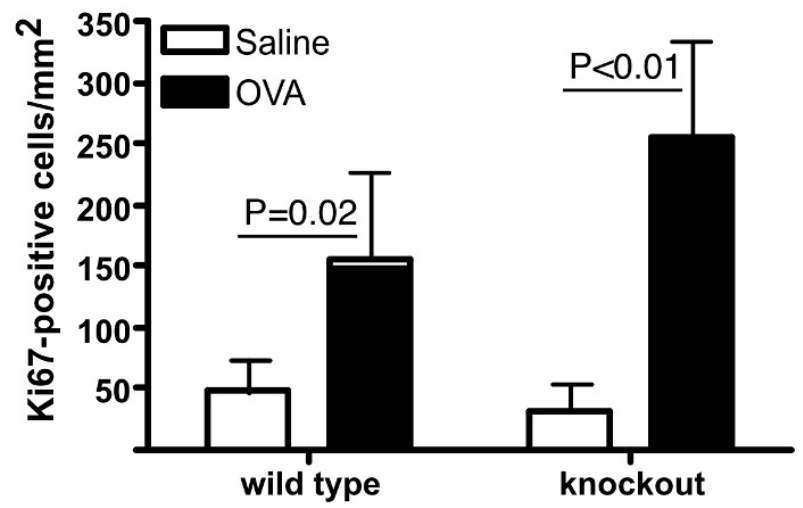

Figure 3

Disease outcomes in arginase II-deficient mice. In A, cell composition of the BALF is shown. Data are from 3-4 mice per group. Representative experiment of 5 ( 2 with Aspergillus and 3 with OVA model) is shown. In $B$, airway hyperresponsiveness is shown. Data are from 4-6 mice per group. In C, collagen content of the lung is shown. Data are mean \pm SD of 4-6 mice per group. In D, quantification of Ki67-positive cells by immunohistochemistry is shown. Data are from 2-5 mice/group. In B-D, two-way ANOVA demonstrated a statistically significant $(P<0.00 \mathrm{I})$ effect of treatment (allergen compared to saline), with no statistically significant effect of genotype or interaction $(P>0.05)$. In $B-D$, a representative experiment of two performed is shown.

lung. These data support the notion that bone marrowderived cells, such as infiltrating inflammatory macrophages, are the main source of the arginase I enzyme, and arginase activity in the allergic lung.

We originally hypothesized that arginase induction has a role in the pathophysiology of allergic airway inflammation. This was based on several findings. First, we and others have shown that arginase expression and function is increased in the lungs of allergen challenged mice and in the lungs and serum of humans with asthma $[7,41]$. However, these studies did not address the specific role of arginase in pathophysiology of the disease. Second, downstream pathways of arginase have been implicated in the regulation of inflammation, collagen deposition, proliferation and airway hyper- responsiveness $[35,42,43]$; these are all hallmark outcomes in asthma. Specifically, Meurs et al have elegantly demonstrated a role for arginase in contractility of allergen-challenged guinea pig tracheas ex vivo. They have also demonstrated that the mechanism for this effect includes arginase-mediated decrease of NO production [44,45]. These results, obtained in guinea pigs and in reductionist $e x$ vivo approaches, differ from our data that were obtained in the complex in vivo environment of allergen challenged mice. We speculate that the difference lies either in the model system (guinea pigs versus mice) or that parallel pathways are invoked in vivo during allergen challenge, thus making the role of arginase redundant. Third, mouse models of parasite infestation, including Schistosome mansoni, Heligmosomoides polygyrus, Leishmania sp, Toxoplasma gondii 
and Nipostrongylus brasiliensis [11-16] demonstrated a role for arginase expression in host defense. Interestingly, in at least one of those publications the role of arginase was confined to models of infection by intracellular pathogens; however, arginase did not play a role in a systemic disease despite induction of arginase in both models [16]. Finally, we have shown a role for arginase in IL-13 induced airway hyperresponsiveness [46] and others have recently suggested a role for arginase in mouse and guinea pig asthma models using arginase inhibitors [17-19]. Specifically, we have shown that delivery of arginase I siRNA to mice that receive IL-13 i.t. leads to decreased arginase I expression and airway responsiveness. It is important to note that this effect was observed at early time points (12-48 hours following single i.t. installation of IL-13). Thus, we speculate that arginase may play a role in airway responsiveness to a single cytokine at early time points when collateral pathways have not been able to develop; in contrast, in allergen challenge multiple pathways are activated that may contribute to airway responsiveness thus making arginase redundant. The study by Maarsingh et al [18], demonstrated that inhalation of $\mathrm{ABH}$, an inhibitor of arginase, protects against allergen-induced airway obstruction, hyperresponsiveness and inflammation. We speculate that our results differ from the ones in this study either because of the different species used (mice versus guinea pigs) or because of the different approach (inhibitors versus genetic ablation of arginase). It is possible that the inhibitor has non-specific off-target effects that may be responsible for the observed effects. It is important to note that arginase plays an important role in the urea cycle in the liver; mutations in arginase leads to severe metabolic consequences in humans and mice, including hyperargininemia, hyperammonemia and premature death $[20,47]$. In an effort to confirm our results, we used an inhibitor of arginase, BEC, and found that it leads to systemic effects, including hyperargininemia (data not shown). Since plasma arginine levels can have profound effects on the immune system $[33,34,48$ 54 ], we elected not to pursue studies with inhibitors as we believed we could not distinguish the effects of arginase inhibition locally in the lungs from indirect effects from arginase inhibition in the liver. In contrast to the study by Maarsingh et al where arginase inhibitor decreased inflammation and airway hyperresponsiveness, Ckless et al [17], found that inhibitor of arginase led to increased inflammation and airway hyperresponsiveness in mouse models of allergic inflammation. Together, these data caution against use of arginase inhibitors in allergic airway inflammation until the effects (specific and off-target) and mechanisms are fully elucidated.

In summary, our data suggest divergent role for arginase I in allergic inflammation compared to parasitic responses. Since arginase is a prominent product of alternatively activated macrophages, which are induced by IL- 4 in both allergic and parasitic responses, our data suggests alterna- tively activated macrophages evolved to combat parasitic infections and are either bystanders in allergic inflammation or have developed other effector molecules for allergic Th2-associated responses.

\section{Conclusion}

Bone marrow cell derived arginase I is the predominant source of allergen-induced lung arginase but is not required for allergen-induced inflammation, airway hyperresponsiveness or collagen deposition.

\section{Abbreviations}

AHR: airway hyperresponsiveness; BALF: bronchoalveolar lavage fluid; BM: bone marrow; BMT: bone marrow transfer; OVA: ovalbumin.

\section{Authors' contributions}

KAN, ARC, ARH and NZ performed the research. SDC and WEO provided critical reagents (arginase I and II-deficient mice, respectively). MWK provided the AHR measurements. MER participated in the conception and design of the study, and helped draft the manuscript. NZ participated in the conception, design and coordination of the study, analyzed the data and drafted the manuscript. All authors read and approved the final manuscript.

\section{Authors' information}

ARC is currently at Oak Brook Allergists in Oak Brook, Illinois. ARH is currently enrolled in the School of Veterinary Medicine, University of Illinois at Champaign-Urbana.

\section{Acknowledgements}

The authors wish to thank Laura Koch for technical assistance, Dr. David Williams, Dr. Jose Cancelas-Perez, Victoria Summey and Jeff Bailey from the CCHMC Comprehensive Mouse and Cancer Core facility for expertise and assistance with bone marrow transplantation, Nicole Mason-Richie for assistance with Ki67 staining, Keith F. Stringer and the CCHMC pathology core for assistance with in situ hybridization, and Jennifer Clark for assistance with APTI measurement. We thank Drs. DeBroski Herbert and Fred Finkelman for helpful discussions and critical reading of the manuscript.

Funding provided by NIH ROI AI53479-0I (to MER and NZ) and March of Dimes grant 6-FY06-I303 (to NZ).

\section{References}

I. Holgate ST: The epidemic of allergy and asthma. Nature 1999, 402:B2-4.

2. Umetsu DT, McIntire IJ, Akbari O, Macaubas $\mathrm{C}$, DeKruyff $\mathrm{RH}$ : Asthma: an epidemic of dysregulated immunity. Nat Immunol 2002, 3:715-720.

3. Busse WW, Lemanske RF Jr: Asthma. N Engl J Med 200I, 344:350-362.

4. Hamelmann E, Gelfand EW: IL-5-induced airway eosinophilia the key to asthma? Immunol Rev 200I, 179:|82-19|.

5. Lee NA, Gelfand EW, Lee JJ: Pulmonary T cells and eosinophils: coconspirators or independent triggers of allergic respiratory pathology? J Allergy Clin Immunol 200 I, 1 07:945-957.

6. Barnes PJ: New directions in allergic diseases: mechanismbased anti-inflammatory therapies. J Allergy Clin Immunol 2000, 106:5-16. 
7. Zimmermann N, King NE, Laporte J, Yang M, Mishra A, Pope SM, Muntel EE, Witte DP, Pegg AA, Foster PS, et al: Dissection of experimental asthma with DNA microarray analysis identifies arginase in asthma pathogenesis. J Clin Invest 2003, II I:1863-1874.

8. Zimmermann N, Mishra A, King NE, Fulkerson PC, Doepker MP, Nikolaidis NM, Kindinger LE, Moulton EA, Aronow BJ, Rothenberg ME: Transcript Signatures in Experimental Asthma: Identification of STAT6-Dependent and -Independent Pathways. J Immunol 2004, 172:1815-1824.

9. Morris SM Jr: Regulation of enzymes of the urea cycle and arginine metabolism. Annual Review of Nutrition 2002, 22:87-105.

10. Mills CD: Macrophage arginine metabolism to ornithine/urea or nitric oxide/citrulline: a life or death issue. Crit Rev Immunol 2001, 21:399-425.

II. Anthony RM, Urban JF Jr, Alem F, Hamed HA, Rozo CT, Boucher JL, Van Rooijen N, Gause WC: Memory T(H)2 cells induce alternatively activated macrophages to mediate protection against nematode parasites. Nat Med 2006, I 2:955-960.

12. Iniesta V, Gomez-Nieto LC, Corraliza I: The inhibition of arginase by $\mathbf{N}$ (omega)-hydroxy-l-arginine controls the growth of Leishmania inside macrophages. J Exp Med 200I, I 93:777-784.

13. Zhao A, Urban JF Ir, Anthony RM, Sun R, Stiltz J, van Rooijen N, Wynn TA, Gause WC, Shea-Donohue T: Th2 cytokine-induced alterations in intestinal smooth muscle function depend on alternatively activated macrophages. Gastroenterology 2008, 135:217-225. e2।I.

14. Hesse M, Modolell M, La Flamme AC, Schito M, Fuentes JM, Cheever AW, Pearce EJ, Wynn TA: Differential regulation of nitric oxide synthase- 2 and arginase-I by type I/type 2 cytokines in vivo: granulomatous pathology is shaped by the pattern of Larginine metabolism. J Immunol 200 I, 167:6533-6544.

15. Rutschman R, Lang R, Hesse M, Ihle JN, Wynn TA, Murray PJ: Cutting edge: Stat6-dependent substrate depletion regulates nitric oxide production. J Immunol 200I, 166:2173-2I77.

16. El Kasmi KC, Qualls JE, Pesce JT, Smith AM, Thompson RW, HenaoTamayo M, Basaraba RJ, Konig T, Schleicher U, Koo MS, et al.: Tolllike receptor-induced arginase $I$ in macrophages thwarts effective immunity against intracellular pathogens. Nat Immunol 2008, 9:1399-1406

17. Ckless K, Lampert A, Reiss J, Kasahara D, Poynter ME, Irvin CG, Lundblad LK, Norton R, Vliet A van der, Janssen-Heininger YM: Inhibition of arginase activity enhances inflammation in mice with allergic airway disease, in association with increases in protein S-nitrosylation and tyrosine nitration. J Immunol 2008, I 8 I:4255-4264.

18. Maarsingh $\mathrm{H}$, Zuidhof AB, Bos IS, van Duin M, Boucher JL, Zaagsma J, Meurs $\mathrm{H}$ : Arginase inhibition protects against allergeninduced airway obstruction, hyperresponsiveness, and inflammation. Am J Respir Crit Care Med 2008, I 78:565-573.

19. Bratt JM, Franzi LM, Linderholm AL, Last MS, Kenyon NJ, Last JA Arginase enzymes in isolated airways from normal and nitric oxide synthase 2-knockout mice exposed to ovalbumin. Toxicol Appl Pharmacol 2009, 234:273-80.

20. lyer RK, Yoo PK, Kern RM, Rozengurt N, Tsoa R, O'Brien WE, Yu H, Grody WW, Cederbaum SD: Mouse model for human arginase deficiency. Mol Cell Biol 2002, 22:4491-4498.

21. Shi O, Morris SM Jr, Zoghbi H, Porter CW, O'Brien WE: Generation of a mouse model for arginase II deficiency by targeted disruption of the arginase II gene. Mol Cell Biol 200 I, 2 I:8I I-8I 3 .

22. Zimmermann N, Hogan SP, Mishra A, Brandt EB, Bodette TR, Pope SM, Finkelman FD, Rothenberg ME: Murine eotaxin-2: a constitutive eosinophil chemokine induced by allergen challenge and IL-4 overexpression. J Immunol 2000, 165:5839-5846.

23. Mishra A, Weaver TE, Beck DC, Rothenberg ME: Interleukin-5mediated allergic airway inflammation inhibits the human surfactant protein $\mathbf{C}$ promoter in transgenic mice. J Biol Chem 200I, 276:8453-8459.

24. Mehlhop PD, Rijn M van de, Goldberg AB, Brewer JP, Kurup VP, Martin TR, Oettgen HC: Allergen-induced bronchial hyperreactivity and eosinophilic inflammation occur in the absence of IgE in a mouse model of asthma. Proceedings of the National Academy of Sciences of the United States of America 1997, 94:1344-1349.

25. Kurup VP, Seymour BW, Choi H, Coffman RL: Particulate Aspergillus fumigatus antigens elicit a TH2 response in
BALB/c mice. Journal of Allergy \& Clinical Immunology 1994, 93: $1013-1020$.

26. Wei LH, Jacobs AT, Morris SM Jr, Ignarro LJ) IL-4 and IL-I 3 upregulate arginase I expression by CAMP and JAK/STAT6 pathways in vascular smooth muscle cells. Am J Physiol Cell Physiol 2000, 279: C248-256.

27. Wei LH, Wu G, Morris SM Jr, Ignarro LJ: Elevated arginase expression in rat aortic smooth muscle cells increases cell proliferation. Proc Natl Acad Sci USA 200I, 98:9260-9264.

28. Li H, Meininger CJ, Kelly KA, Hawker JR Jr, Morris SM Jr, Wu G: Activities of arginase $I$ and II are limiting for endothelial cell proliferation. Am J Physiol Regul Integr Comp Physiol 2002, 282:R64-R69.

29. Kohl J, Baelder R, Lewkowich IP, Pandey MK, Hawlisch H, Wang L, Best J, Herman NS, Sproles AA, Zwirner J, et al.: A regulatory role for the $\mathbf{C 5 a}$ anaphylatoxin in type $\mathbf{2}$ immunity in asthma. J Clin Invest 2006, I 16:783-796.

30. Wills-Karp M, Luyimbazi J, Xu X, Schofield B, Neben TY, Karp CL, Donaldson DD: Interleukin- 13: central mediator of allergic asthma. Science 1998, 282:2258-2261.

3I. Fulkerson PC, Fischetti CA, Hassman LM, Nikolaidis NM, Rothenberg ME: Persistent effects induced by IL- 13 in the lung. Am J Respir Cell Mol Biol 2006, 35:337-346.

32. Rothenberg ME, Doepker MP, Lewkowich IP, Chiaramonte MG Stringer KF, Finkelman FD, MacLeod CL, Ellies LG, Zimmermann N: Cationic amino acid transporter 2 regulates inflammatory homeostasis in the lung. Proc Natl Acad Sci USA 2006, 103:14895-14900.

33. de Jonge WJ, Hallemeesch MM, Kwikkers KL, Ruijter JM, de Gier-de Vries C, van Roon MA, Meijer AJ, Marescau B, de Deyn PP, Deutz NE, Lamers WH: Overexpression of arginase I in enterocytes of transgenic mice elicits a selective arginine deficiency and affects skin, muscle, and lymphoid development. Am J Clin Nutr 2002, 76: 128-140.

34. de Jonge WJ, Kwikkers KL, te Velde AA, van Deventer SJ, Nolte MA, Mebius RE, Ruijter JM, Lamers MC, Lamers WH: Arginine deficiency affects early B cell maturation and lymphoid organ development in transgenic mice. J Clin Invest 2002, I 10:1539-1548

35. Wu G, Morris SM Jr: Arginine metabolism: nitric oxide and beyond. Biochem J 1998, 336(Pt I): I- I7.

36. Albina JE, Abate JA, Mastrofrancesco B: Role of ornithine as a proline precursor in healing wounds. J Surg Res 1993, 55:97-102.

37. Kershenobich D, Fierro FJ, Rojkind M: The relationship between the free pool of proline and collagen content in human liver cirrhosis. J Clin Invest 1970, 49:2246-2249.

38. Lindemann D, Racke K: Glucocorticoid inhibition of interleukin4 (IL-4) and interleukin-I3 (IL-I3) induced up-regulation of arginase in rat airway fibroblasts. Naunyn Schmiedebergs Arch Pharmacol 2003, 368:546-550.

39. Que LG, Kantrow SP, Jenkinson CP, Piantadosi CA, Huang YC: Induction of arginase isoforms in the lung during hyperoxia. Am J Physiol 1998, 275:L96-102.

40. Takemoto K, Ogino K, Shibamori M, Gondo T, Hitomi Y, Takigawa $T$, Wang DH, Takaki J, Ichimura $H$, Fujikura $Y$, Ishiyama $H$ : Transiently, paralleled upregulation of arginase and nitric oxide synthase and the effect of both enzymes on the pathology of asthma. Am J Physiol Lung Cell Mol Physiol 2007, 293:L1419-1426.

4I. Morris CR, Poljakovic M, Lavrisha L, Machado L, Kuypers FA, Morris SMJr: Decreased arginine bioavailability and increased serum arginase activity in asthma. Am J Respir Crit Care Med 2004, I70:148-153.

42. Meurs H, Maarsingh H, Zaagsma J: Arginase and asthma: novel insights into nitric oxide homeostasis and airway hyperresponsiveness. Trends Pharmacol Sci 2003, 24:450-455

43. King NE, Rothenberg ME, Zimmermann N: Arginine in asthma and lung inflammation. I Nutr 2004, 1 34:2830S-2836S. discussion $2853 \mathrm{~S}$

44. Meurs H, Hamer MA, Pethe S, Vadon-Le Goff S, Boucher JL, Zaagsma $\mathrm{J}$ : Modulation of cholinergic airway reactivity and nitric oxide production by endogenous arginase activity. $\mathrm{Br} J$ Pharmacol 2000, 130:1793-1798.

45. Meurs H, McKay S, Maarsingh H, Hamer MA, Macic L, Molendijk N, Zaagsma J: Increased arginase activity underlies allergeninduced deficiency of cNOS-derived nitric oxide and airway hyperresponsiveness. BrJ Pharmacol 2002, I36:39|-398. 
46. Yang M, Rangasamy D, Matthaei KI, Frew AJ, Zimmermann N, Mahalingam S, Webb DC, Tremethick DJ, Thompson PJ, Hogan SP, et al.: Inhibition of Arginase I Activity by RNA Interference Attenuates IL- I 3-Induced Airways Hyperresponsiveness. J Immunol 2006, 177:5595-5603.

47. lyer R, Jenkinson CP, Vockley JG, Kern RM, Grody WW, Cederbaum $S$ : The human arginases and arginase deficiency. J Inherit Metab Dis 1998, 2I(Suppl I):86-100.

48. Luiking YC, Poeze M, Ramsay G, Deutz NE: The role of arginine in infection and sepsis. JPEN J Parenter Enteral Nutr 2005, 29:S70-74.

49. Popovic PJ, Zeh HJ 3rd, Ochoa JB: Arginine and immunity. J Nutr 2007, 137:168IS-1686S

50. Rodriguez PC, Zea AH, Culotta KS, Zabaleta J, Ochoa JB, Ochoa AC: Regulation of $T$ cell receptor $C D 3 z$ zeta chain expression by $L$ arginine. J Biol Chem 2002, 277:2 I I 23-2I I 29.

5I. Rodriguez PC, Zea AH, DeSalvo J, Culotta KS, Zabaleta J, Quiceno DG, Ochoa JB, Ochoa AC: L-arginine consumption by macrophages modulates the expression of CD3zeta chain in T lymphocytes. J Immunol 2003, 171:1232-1239.

52. Kobayashi T, Yamamoto M, Hiroi T, McGhee J, Takeshita Y, Kiyono $\mathrm{H}$ : Arginine enhances induction of $\mathbf{T}$ helper $I$ and $T$ helper 2 cytokine synthesis by Peyer's patch alpha beta $T$ cells and antigen-specific mucosal immune response. Biosci Biotechnol Biochem 1998, 62:2334-2340.

53. Takano H, Lim HB, Miyabara Y, Ichinose T, Yoshikawa T, Sagai M: Oral administration of L-arginine potentiates allergeninduced airway inflammation and expression of interleukin5 in mice. J Pharmacol Exp Ther 1998, 286:767-77|.

54. Sapienza MA, Kharitonov SA, Horvath I, Chung KF, Barnes PJ: Effect of inhaled $L$-arginine on exhaled nitric oxide in normal and asthmatic subjects. Thorax 1998, 53:172-175.

Publish with Biomed Central and every scientist can read your work free of charge

"BioMed Central will be the most significant development for disseminating the results of biomedical research in our lifetime. "

Sir Paul Nurse, Cancer Research UK

Your research papers will be:

- available free of charge to the entire biomedical community

- peer reviewed and published immediately upon acceptance

- cited in PubMed and archived on PubMed Central

- yours - you keep the copyright

Submit your manuscript here:

http://www.biomedcentral.com/info/publishing_adv.asp
BiolMedcentral 